\title{
Altura e diâmetro de Eucalyptus citriodora e $E$. grandis, submetidos a diferentes teores de água em convivência com Brachiaria brizantha
}

\author{
WILSON DA SiLva* \\ Antônio Alberto da Silva** \\ Tocio Sediyama** \\ Luís HenRique LoPes de Freitas****
}

\begin{abstract}
RESUMO
Objetivou-se avaliar, em casa de vegetação, altura e diâmetro do caule de plantas de duas espécies de eucalipto, cultivadas em solo com três teores de água, junto a quatro populações de $B$. brizantha. Utilizou-se o delineamento experimental em blocos ao acaso, com quatro repetições, em arranjo fatorial $(2 \times 3 \times 4)$ : duas espécies $(E$. citriodora e $E$. grandis), três teores de água (20, 23 e $26 \%$ ) e quatro populações de $B$. brizantha (0, 1, 2 e 3 plantas/vaso). Manteve-se teor constante de água nos vasos, até a última avaliação do experimento. Esse controle foi feito utilizando-se microtensiômetro e pesagens diárias, com reposição da água evapotranspirada. Os maiores valores de altura total e diâmetro do caule das plantas de E. citriodora e E. grandis foram observados em solos com maior teor de água no solo (26\%), em ausência $B$. brizantha. A presença $B$. brizantha reduziu a altura total e o diâmetro do caule dos eucaliptos para os três teores de água no solo. Todavia, a maior redução percentual, tanto da altura quanto do diâmetro, ocorreu quando as plantas dos eucaliptos foram submetidas a $26 \%$ de água no solo. E. citriodora foi mais sensível à convivência com $B$. brizantha que $E$. grandis.
\end{abstract}

Palavras-chave: Eucalyptus, Brachiaria brizantha, competição, umidade no solo

\section{ABSTRACT}

Eucalyptus citriodora and E. grandis height and diameter growing in different water and association levels with Brachiaria brizantha. Height and diameter of two species of eucalypts, cultivated in substract with three water contents, jointly with four $B$. brizantha populations, in greenhouse conditions, were evaluated. Treatments were arranged in a factorial design, with four replications $(2 \times 3 \times 4)$ : two species of

\footnotetext{
* Doutor em Fitotecnia, Dep. de Fitotecnia da UFV;

** Prof. do Dep. de Fitotecnia da UFV;

*** Téc. em Agropecuária do Dep. de Fitotecnia da UFV
} 
eucalypts (E. citriodora and E. grandis), three soil water contents (20,23 and 26\%) and four $B$. brizantha populations $(0,1,2$, and 3 plants/vase). Water content was maintained constant until experiment last evaluation. This control was done using daily weightings and tensiometer, with evapotranspired water reposition. The total height and diameter and values of E. citriodora and E. grandis plants stems were observed in the soils with the highest water content $(26 \%)$ in $B$. brizantha absence. B. brizantha presence reduced total higher and diameter of eucalypts stems for the three water contents in the soil. However, the heighest percentual reduction, both in height and diameter, occurred when eucalypts plants were subjected to $26 \%$ water in the soil. E. citriodora was more sensible to association with $B$. brizantha than $E$. grandis.

Key words: Eucalyptus, Brachiaria brizantha, competition, soil moisture.

\section{INTRODUÇÃO}

A cultura do eucalipto manifesta alta sensibilidade à competição por água, luz e nutrientes com as plantas daninhas na fase de implantação de povoamento, particularmente com espécies de rápido crescimento, como as gramíneas. Com esse efeito, a ausência de controle ou manejo inadequado dessas invasoras, nos estádios iniciais da cultura, pode implicar em elevadas perdas na produtividade florestal (SILVA, 1993).

Estudos realizados por PITELLI e KARAN (1988), mostraram que os efeitos da interferência das plantas daninhas, durante o primeiro ano do crescimento de Eucalyptus pellita, foram mais drásticas no período de abril a setembro, quando ocorreu severa restrição hídrica na região.

HSIAO e ACEVEDO (1974) relatam que as plantas são organismos altamente integrados e, à medida que o estresse afeta algum processo na planta, vários mecanismos de controle podem ser ativados, visando ajustar outros processos para manter um equilíbrio ou fazer frente ao problema. O estresse hídrico afeta todos os aspectos de crescimento da planta, incluindo a anatomia, morfologia, fisiologia e bioquímica (KRAMER, 1983). Segundo (GHOLZ et al. 1990) a disponibilidade de água afeta o crescimento das plantas, por controlar a abertura dos estômatos e, consequentemente, a produção de matéria seca. $\mathrm{O}$ decréscimo de água no solo diminui o potencial de água na folha e sua condutância estomática, promovendo o fechamento dos estômatos. Esse fechamento bloqueia o influxo de $\mathrm{CO}_{2}$ para as folhas, afetando o acúmulo de fotoassimilados, o que implica redução do crescimento e da produtividade. TYREE et al. (1987) salientam que embora a fotossíntese possa diminuir, independente ao fechamento dos estômatos, o efeito do déficit hídrico sobre esse fechamento é o que mais contribui para a redução da assimilação de $\mathrm{CO}_{2} \mathrm{e}$, consequentemente, para o crescimento da planta.

O grau de redução do crescimento e produção, causado pelo déficit hídrico, por meio da diminuição da área foliar, depende da relação entre a taxa de extensão e potencial de água da folha durante o estresse, e na recuperação após a chuva ou irrigação (HSIAO, 1973). Sob estresse hídrico, as folhas novas 
desenvolvem-se mais lentamente (aumento do plastrocromo), e as folhas velhas senescem mais rapidamente $\mathrm{e}, \mathrm{em}$ conseqüência há redução da área fotossintética $\mathrm{e}$ da taxa de fotossíntese por unidade de área foliar (KRAMER, 1983).

Acredita-se que a competição das plantas daninhas pela água no solo com a cultura possa afetar em maior escala a altura e o diâmetro de plantas que estão crescendo com menor disponibilidade de água no solo. Esse trabalho objetivou-se avaliar o crescimento em altura e diâmetro do caule de $E$. citriodora e E. grandis, em resposta a teores de água no solo e à convivência ou não com diferentes populações de $B$. brizantha .

\section{MATERIAL E MÉTODOS}

O experimento foi conduzido em condições de casa de vegetação, da Universidade Federal de Viçosa, Viçosa, MG. O solo utilizado no experimento foi Podzólico Vermelho-Amarelo câmbico, fase terraço, apresentando textura argiloarenosa, com $38 \%$ de areia grossa, $15 \%$ de areia fina, $10 \%$ de silte e $37 \%$ de argila (EMBRAPA, 1997); carbono orgânico 3,0\% (DEFELIPO e RIBEIRO, 1981) e $\mathrm{pH} 5,8$, tendo sido coletado sob floresta nativa, à profundidade de $0-20 \mathrm{~cm}$. A curva característica de umidade desse solo (Fig. 1), foi determinada utilizando-se o aparelho de membrana de pressão de RICHARDS (1949). Essa curva foi utilizada para a determinação da quantidade de água a ser adicionada/vaso.

Após o preparo, as mostras de solo foram colocadas em vasos de plástico com capacidade para $3,25 \mathrm{~kg}$. Os quais foram recobertos internamente com polietileno de $0,05 \mathrm{~mm}$ de espessura, para se evitar a perda de água por percolação. Após estabelecer os três teores de água no solo, para os diferentes tratamentos, conforme a Tabela 1, fez-se o transplante das mudas de Eucalyptus citriodora e $E$. grandis e das mudas de Brachiaria brizantha nas populações estudadas. No momento do transplante as mudas de eucalipto se encontravam com aproximadamente $20 \mathrm{~cm}$ de altura, e às de $B$. brizantha, com quatro folhas. O nível de água no solo foi mantido constante, durante toda a condução do experimento (70 dias após o transplante das mudas), fazendo-se a reposição da água evapotranspirada. Para esse controle utilizou-se um minitanque "classe A", microtensiômetro e pesagens diária, com reposições da água evapotranspirada realizadas às $8 \mathrm{~h}, 13 \mathrm{~h}$ e $16 \mathrm{~h} \mathrm{30}$. Observou-se, ainda, dentro da casa de vegetação os seguintes valores médios quanto a: evaporação potencial $(378,4 \mathrm{~mL})$, temperatura máxima $\left(34,7^{\circ} \mathrm{C}\right)$, temperatura mínima $\left(21,0^{\circ} \mathrm{C}\right)$, umidade relativa do ar às $7 \mathrm{~h} 30(83,6 \%)$ e às $14 \mathrm{~h}(56,2 \%)$.

O experimento foi constituído de 24 tratamentos, compreendendo duas espécies de eucalipto (Eucalyptus citriodora e Eucalyptus grandis); três teores de água (condições próximo ao estresse, 20\%; intermediária, 23\%; e condições próximo à capacidade de campo, 26\%); e quatro populações de Brachiaria brizantha (0, 1, 2 e 3 plantas/vaso). O delineamento adotado foi o de blocos ao acaso, com parcelas subdivididas pelas épocas de avaliação, em esquema fatorial 
( $2 \times 3 \times 4)$, com quatro repetições e uma planta de eucalipto por unidade experimental (vaso), totalizando 96 unidades experimentais.

Fez-se a complementação da fertilização, durante a condução do experimento, aplicando-se, alternativamente, a cada 7 dias, solução nutritiva de CLARK (1975) e a formulação 20-05-20 (N, P, K). Dessa forma, o total dos nutrientes aplicados por vaso foi de: $278 \mathrm{mg}$ de N; $62 \mathrm{mg}$ de P; $265 \mathrm{mg}$ de K; $31 \mathrm{mg}$ de $\mathrm{Ca}$ e $5 \mathrm{mg}$ de $\mathrm{Mg}$.

Figura 1 - Curva de retenção da água para o solo utilizado

Figure 1 - Water retention curve for the soil utilized

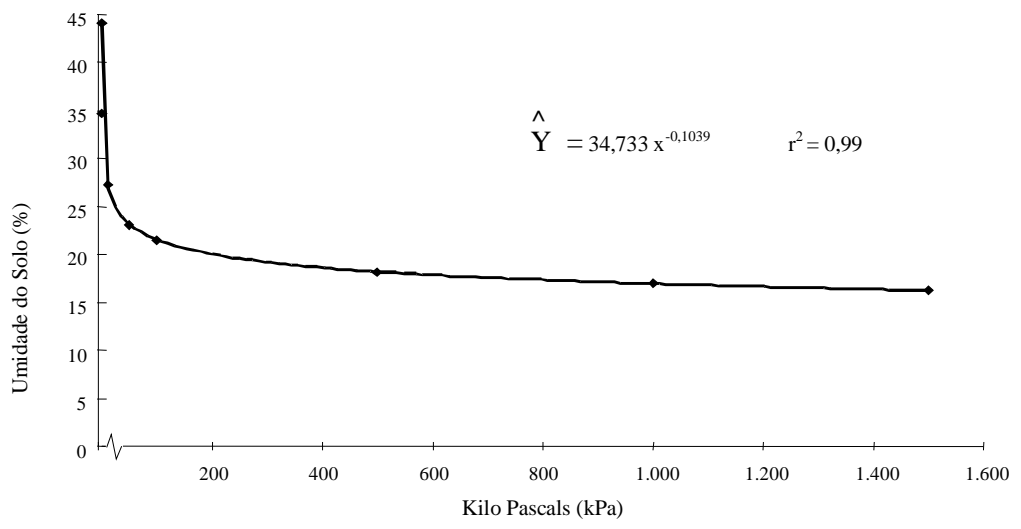

Tabela 1 - Umidade residual do solo; tensão de água no solo, mantida após o transplante das mudas; porcentagem do nível de água correspondente; e quantidade de água adicionada por vaso

Table 1 - Soil residual moisture, maintained water tension in the soil after seedlings transplantation, corresponding water moisture percent, and water mass added per vase

\begin{tabular}{|c|c|c|c|}
\hline $\begin{array}{c}\text { Umidade } \\
\text { Residual do solo, } \\
\text { antes do } \\
\text { transplante } \\
(\%) \\
\end{array}$ & $\begin{array}{l}\text { Tensão de água no solo } \\
\text { mantido após o } \\
\text { transplante das mudas }\end{array}$ & $\begin{array}{l}\text { Nível de água no } \\
\text { solo mantido após o } \\
\text { transplante das } \\
\text { mudas } \\
\text { (\% em massa) }\end{array}$ & $\begin{array}{l}\text { Quantidade de água } \\
\text { adicionada/vaso e } \\
\text { mantida após o } \\
\text { transplante das } \\
\text { mudas } \\
(\mathrm{g})\end{array}$ \\
\hline 10,5 & 202,8 & 20 & 250 \\
\hline 10,5 & 49, & $2 ?$ & 32 \\
\hline 10,5 & 16,2 & 26 & 400 \\
\hline
\end{tabular}

Foram feitas medições de altura total e diâmetro do caule no dia do transplante das mudas e aos $7,14,21,28,35,42,49,56,63$ e 70 dias após o transplante das mudas. Os diâmetros foram medidos a $5 \mathrm{~cm}$ do nível do solo.

Foram ajustadas equações de regressão múltipla para a altura e o diâmetro das plantas, em função do teor de água no solo e épocas de avaliação, 
tratamentos quantitativos, com base na significância do valor de $\mathrm{F}$, a 5 e $1 \%$ de probabilidade.

\section{RESULTADOS E DISCUSSÃO}

\section{ALTURA DAS PLANTAS}

As equações regressão apresentadas na Figura 2, permitiram evidenciar que houve efeito quadrático do teor de água no solo e linear da época avaliada no crescimento em altura das plantas de E. citriodora. Para E. grandis, a resposta foi o inverso, houve efeito linear da água no solo e quadrático da época de avaliação (dias após o transplante das mudas). Aos 70 dias após o transplante das mudas, $E$. citriodora alcançou altura estimada de $82,1 \mathrm{~cm}$ em solo com $26 \%$ de água e 67,0 $\mathrm{cm}$ com $20 \%$ de água (Figura 2). Para E. grandis, o máximo de altura estimada foi de $75,1 \mathrm{~cm}$ em solo com $26 \%$ de água e $65,1 \mathrm{~cm}$ com $20 \%$ de água no solo aos 70 dias após o transplante.

A diminuição no teor de água no solo, de $26 \%$ (próximo à capacidade de campo) para $20 \%$ (condições próximo ao estresse hídrico), reduziu em 18,4\% a altura do E. citriodora e em 13,3\% a do E. grandis, independente da densidade da população de $B$. brizantha. Esta redução da altura das plantas é explicada por PEREIRA (1979), o qual afirma que o déficit hídrico afeta a altura da planta reduzindo o alongamento do caule, o número das folhas e o crescimento cambial.

Segundo SILVA (1997) o estresse hídrico reduziu a taxa fotossintética líquida, a condutância estomática, a taxa transpiratória, a área foliar e a biomassa seca. De acordo com esse autor, à medida que se aumentou o teor de água no solo, de $20 \%$ para $26 \%$, essas características alcançaram maiores valores, principalmente, em ausência de $B$. brizantha no vaso, o que pode contribuir para maior altura e diâmetro das plantas dos eucaliptos.

A Figura 3 apresenta as equações, que mostram a influência da população de plantas de $B$. brizantha/vaso, na altura dos eucaliptos, em função da época de avaliação. Verifica-se, o efeito linear para época de avaliação. O máximo da altura estimada de E. citriodora foi de $98,9 \mathrm{~cm}$, a de $E$. grandis $\mathrm{em} 79,6 \mathrm{~cm}$, em ausência de $B$. brizantha, aos 70 dias após o transplante das mudas. Em presença de uma planta de $B$. brizantha, a altura das plantas caiu para $73,3 \mathrm{~cm}$ em $E$. citriodora e para $68,2 \mathrm{~cm}$ em E. grandis. À medida que aumentou a população de B. brizantha, isto é, de uma planta para duas e três plantas/vaso, a altura máxima alcançada para as plantas de eucalipto reduziu ainda mais, 62,7 e 59,3 cm em E. citriodora, e 64,6 e $65,3 \mathrm{~cm}$ em $E$. grandis, respectivamente, aos 70 dias após o transplante das mudas.

Sendo assim, a presença de $B$. Brizantha reduziu a altura das plantas dos eucaliptos em percentuais que variaram de 25,9 a $40,0 \%$ para $E$. citriodora e de 14,3 a $18,8 \%$ para $E$. grandis. Dessa forma, em presença da gramínea, pode-se deduzir que E. citriodora é mais sensível à competição por água que E. grandis. Para LOCATELLY e DOOL (1977), a competição por água é uma das mais importantes e, muitas vezes, supera a competição por nutrientes. De acordo com 
BARLOW (1983), à medida que a disponibilidade de água no solo decresce, a taxa de transpiração diminui como resultado do fechamento dos estômatos. Este é um dos importantes mecanismos de defesa que as plantas apresentam contra as perdas exageradas de água e a eventual morte por dessecação.

Figura 2 - Altura das plantas de E. citriodora e E. grandis, em resposta a 20, 23 e $26 \%$ de água no solo e dias após o transplante das mudas, independente da população de $B$. brizantha

Figure 2 - E. citriodora and E. grandis plant height in response to 20, 23 and $26 \%$ of water in the soil and days after seedling transplantation, regardless the population of B. brizantha
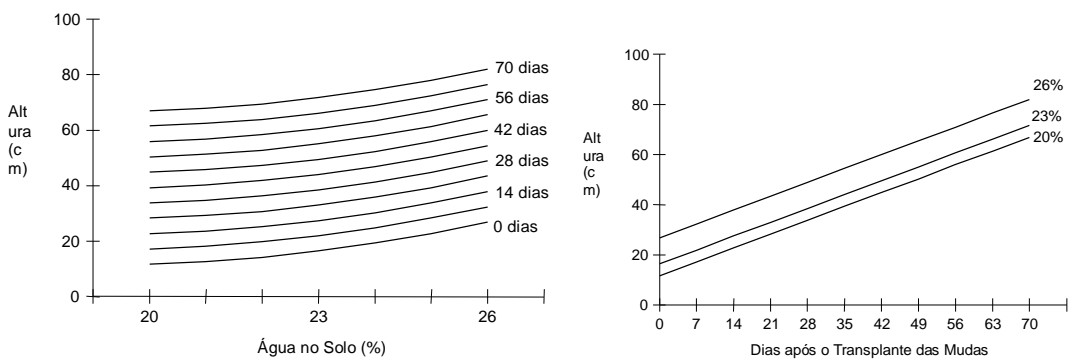

E. citriodora $\$=125,8470-12,0384 * \mathrm{X}+0,3165 * * \mathrm{X}^{2}+0,7899 * * \mathrm{D} \quad \mathrm{r}^{2}=0,95$
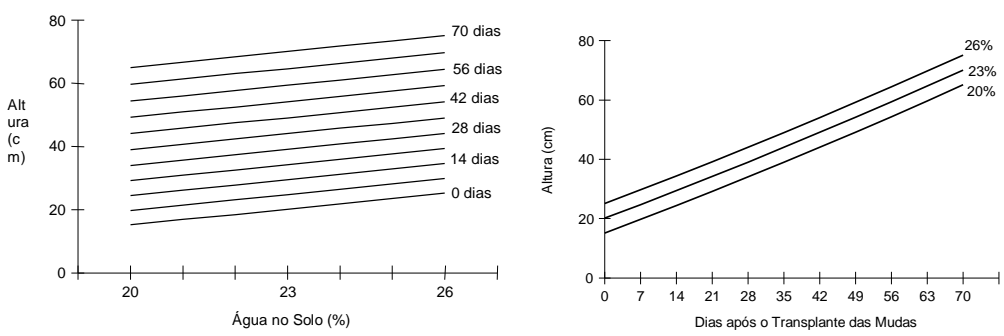

E. grandis $\$=-18,2509+1,6695 * * \mathrm{X}+0,6516 * * \mathrm{D}+0,0008801 * * \mathrm{D}^{2}$ $\mathrm{R}^{2}=0,98$ 
Figura 3 - Altura das plantas de E. citriodora e E. grandis, em ausência e em presença de uma, duas e três plantas de $B$. brizantha/vaso, em resposta a dias após o transplante das mudas, independente dos teores de água no solo

Figure 3 - E. citriodora and E. grandis plant height in absence and presence of one, two and three plants of $B$. brizantha/vase, in response to days after seedling transplantation, regardless the water content in the soil

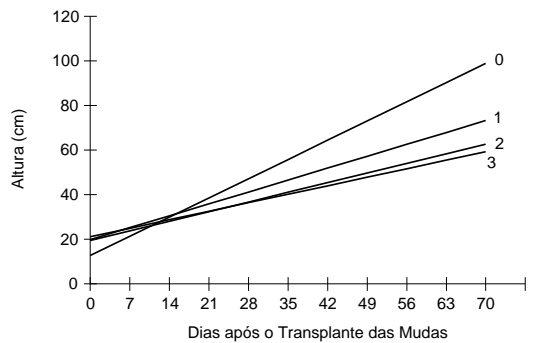

E. citriodora

0 B. brizantha $\$=12,6724+1,2322 * * \mathrm{D} \mathrm{r}^{2}=0,96$

1B. brizantha $\$=19,8258+0,7641 * * \mathrm{D} \mathrm{r}^{2}=0,97$

2 B. brizantha $\$=19,4394+0,6176 * * \mathrm{D} \mathrm{r}^{2}=0,98$

3 B. brizantha $\$=21,1288+0,5457 * * \mathrm{D} \mathrm{r}^{2}=0,98$

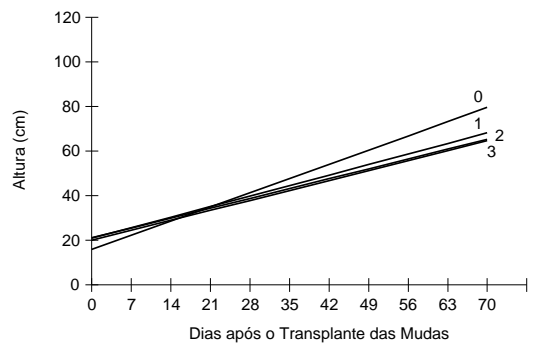

E. grandis

0 B. brizantha $\$=15,9375+0,9089 * * \mathrm{D} \mathrm{r}^{2}=0,97$

1 B. brizantha $\$=20,9261+0,6750 * * \mathrm{D} \mathrm{r}^{2}=0,99$

2 B. brizantha $\$=20,0303+0,6371 * * \mathrm{D} \mathrm{r}^{2}=0,98$

3 B. brizantha $\$=21,1098+0,6319 * * \mathrm{D} \mathrm{r}^{2}=0,99$

A análise do crescimento em altura das plantas dos eucaliptos, em ausência de $B$. brizantha, apresentou equação de regressão múltipla, com superfície de resposta (Figura 4). A equação indica efeito linear para teor de água no solo e época de avaliação. Para o maior teor de água (26\%), obteve-se o máximo estimado de altura com $99,4 \mathrm{~cm}$, enquanto a $20 \%$ de água (condições sob estresse hídrico), o máximo estimado foi de $79,1 \mathrm{~cm}$, aos 70 dias após o transplante das mudas. Os modelos ajustados contribuíram com uma aproximação do fenômeno, para a altura dos eucaliptos, convivendo com B. brizantha, obtendo-se, assim, a equação de regressão múltipla, com superfície de resposta. Tanto em presença de uma, quanto em presença de duas ou três plantas de B. brizantha/vaso, contribuíram com efeito quadrático para água no solo e linear para época de avaliação. 
Figura 4 - Altura de plantas de eucalipto, em ausência e presença de uma, duas e três plantas de $B$. brizantha/vaso, em resposta a 20,23 e $26 \%$ de água no solo e dias após o transplante de mudas, independente da espécie de eucalipto

Figure 4 - Eucalyptus plants height in absence and presence of one, two and three plants of B. brizantha/vase, in response to 20,23 and $26 \%$ of water in the soil, and 70 days after seedlings' transplantation, regardless the eucalyptus species
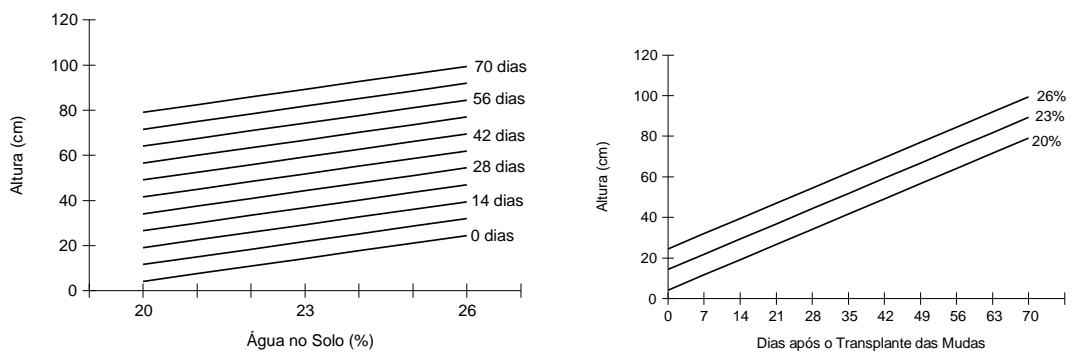

0 B. brizantha $\$=-63,7121+3,3921 * * \mathrm{X}+1,0706 * * \mathrm{D} \quad \mathrm{R}^{2}=0,94$
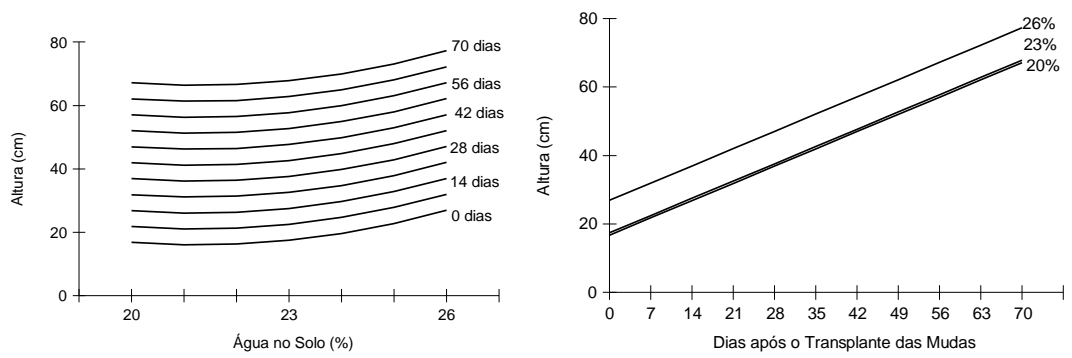

1 B. brizantha $\stackrel{\$}{\$}=235,8630-20,6841 * * X+0,4864 * * X^{2}+0,7196 * * D \quad R^{2}=0,96$
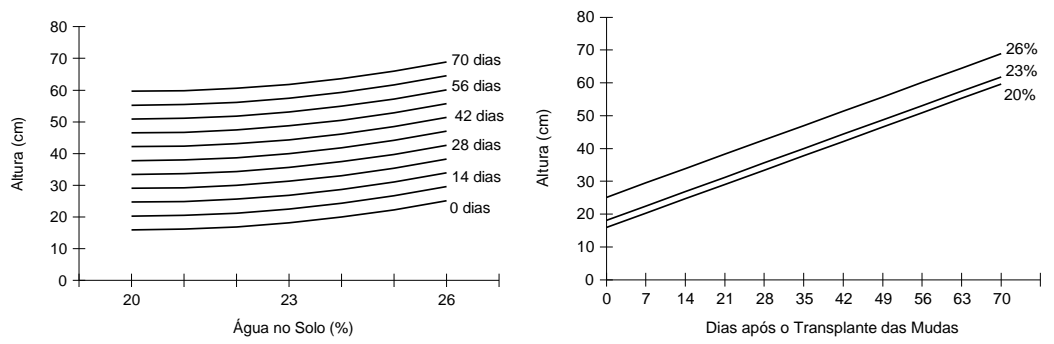

2 B. brizantha $\$=125,0230-10,8337 * * \mathrm{X}+0,2689 * * \mathrm{X}^{2}+0,6274 * * \mathrm{D} \quad \mathrm{R}^{2}=0,96$ 

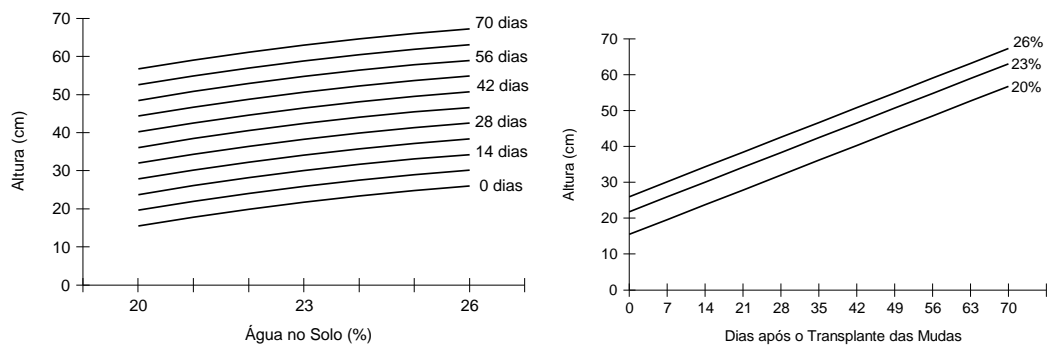

3 B. brizantha $\$=78,6582+6,9818 * * \mathrm{X}-0,1137 * * \mathrm{X}^{2}+0,5888 * * \mathrm{D}$

$\mathrm{R}^{2}=0,97$

Analisando-se os resultados para as duas espécies, verifica-se redução de $20,4 \%$ na altura dos eucaliptos, quando se comparou o valor do maior teor de água (26\%), ao menor nível (20\%). Esses dados evidenciam que, aumentando-se a população de plantas de $B$. brizantha/vaso, ocorre redução na altura máxima. Essa redução passa a ser maior quando os teores de água no solo diminuem. Em condições de $26 \%$ de água no solo, a altura máxima estimada dos eucaliptos em convivência com uma, duas e três plantas de $B$. brizantha/vaso, foi de 77,3, 69,0 e $67,2 \mathrm{~cm}$, respectivamente, aos 70 dias após o transplante das mudas. Em ausência de $B$. brizantha, a altura máxima estimada foi de $99,4 \mathrm{~cm}$. Em relação a altura máxima das plantas de eucalipto obtida em ausência de $B$. brizantha, a presença uma, duas e três plantas/vaso de $B$. brizantha, acarretou uma redução na altura dos eucaliptos em $22,2 \% ; 30,6 \%$ e $32,4 \%$, respectivamente.

Sob estresse hídrico (20\%), a altura máxima estimada das plantas de eucalipto foi de $67,1 \mathrm{~cm} ; 59,8 \mathrm{~cm}$; e $56,7 \mathrm{~cm}$ para uma, duas e três plantas de $B$. brizantha/vaso, respectivamente. Em ausência de $B$. brizantha, essa altura atingiu $79,1 \mathrm{~cm}$. Em termos percentuais, a redução da altura máxima foi de 15,2\%, 24,4\% e $28,3 \%$ em convivência com uma, duas e três plantas de B. brizantha/vaso, aos 70 dias após o transplante das mudas. VOELLER et al. (1974), afirmaram ser a água o fator de competição mais importante entre as gramíneas e a espécie florestal em crescimento, porque as raízes das gramíneas apresentam desenvolvimento mais rápido e são capazes de reduzir o teor de água do solo a tensões menores que aquelas que o Pinus tem condições de absorver, quando esta espécie estáem crescimento.

\section{DIÂMETRO DO CAULE}

A avaliação do diâmetro do caule de E. citriodora e de $E$. grandis, em função da umidade no solo e da época de avaliação, é representa na Figura 5. Observa-se nesta Figura que houve efeito quadrático do teor de água no solo e linear da época de avaliação (dias após o transplante das mudas), para ambas as espécies. Verificou-se que o teor maior de água no solo (26\%) proporcionou diâmetro máximo estimado de 4,9 mm para E. citriodora. No solo com $20 \%$ de água, o diâmetro do caule de E. citriodora foi estimado em 4,2 mm, aos 70 dias após o transplante das mudas. Com relação ao E. grandis, o diâmetro máximo estimado foi de 7,0 mm no solo com $26 \%$ de água, e de 5,3 $\mathrm{mm}$ com $20 \%$ de água, também aos 70 dias após o transplante das mudas. 
Figura 5 - Diâmetro das plantas de E. citriodora e E. grandis, em resposta a 20, 23 e $26 \%$ de água no solo e dias após o transplante de mudas, independente da população de B. brizantha Figure 5 - E. citriodora and E. grandis diameter in response to 20, 23 and $26 \%$ of water in the soil and to 70 days after seedling transplantation, regardless the population of B. brizantha
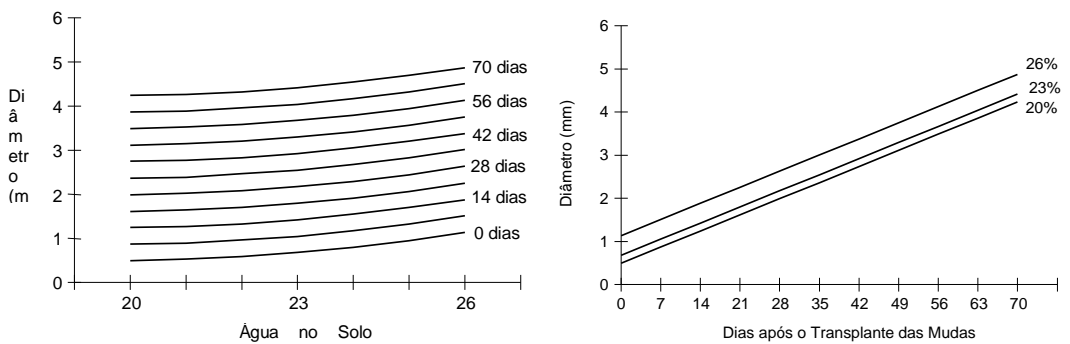

E. citriodora $\$=6,3266-0,5977 * * \mathrm{X}+0,01531 * * \mathrm{X}^{2}+0,05343 * * \mathrm{D}$ $\mathrm{R}^{2}=0,92$
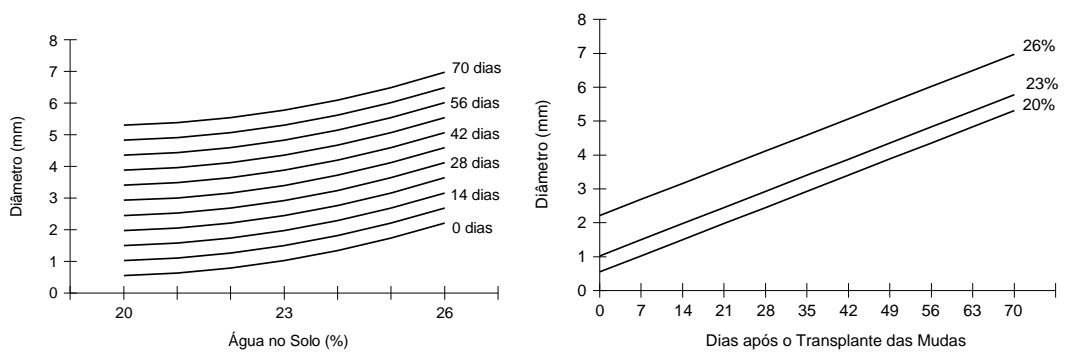

E. grandis $\$=15,6825-1,5521 * * \mathrm{X}+0,03977 * \mathrm{X}^{2}+0,06799 * * \mathrm{D}$

$$
\mathrm{R}^{2}=0,95
$$

Ressalta-se que houve redução do diâmetro do caule no solo com estresse hídrico (20\% de água) em relação ao solo mais úmido (26\% de água). Essa redução foi de $14,3 \%$ para E. citriodora e $24,3 \%$ para $E$. grandis. Dessa forma, E. grandis cresceu mais em diâmetro e a sua redução foi mais elevada $(24,3 \%)$ com a diminuição do teor de água no solo do que a de E. citriodora (14,3\%). Segundo KUHNS e GJERSTAD (1988), o estresse hídrico afeta a força da fonte e do dreno por seus efeitos sobre a fotossíntese, a translocação, o crescimento e o metabolismo geral. À medida que há déficit de água no solo, as raízes desenvolvem-se para suprira exigência de água e nutrientes pela planta (NAMBIAR, 1984). De acordo com TSCHAPLINSKI(1982), havendo restrição ao desenvolvimentoradicular, a planta poderá sofrer coma deficiênciahídrica.

Figura 6 - Diâmetro das plantas de eucalipto, em resposta a 20, 23 e 26\% de água no solo e dias após o transplante de mudas, para as população de $B$. brizantha 
Figure 6 -Eucalypts plants diameterin response to 20, 23 and 26\% of water in the soil and to 70 days after seedlings' transplantation, regardless the population of B. brizantha
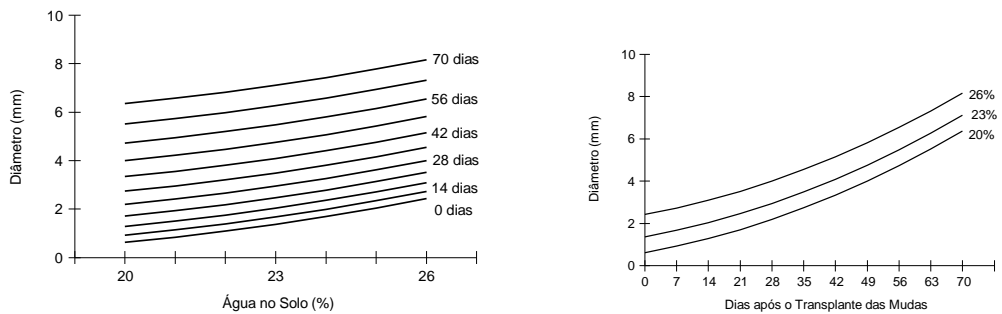

0 B. brizantha

$\$=3,4628-0,4830 * * \mathrm{X}+0,01705 * * \mathrm{X}^{2}+0,03905 * * \mathrm{D}+0,0006130 * * \mathrm{D}^{2} \quad \mathrm{R}^{2}=0,95$
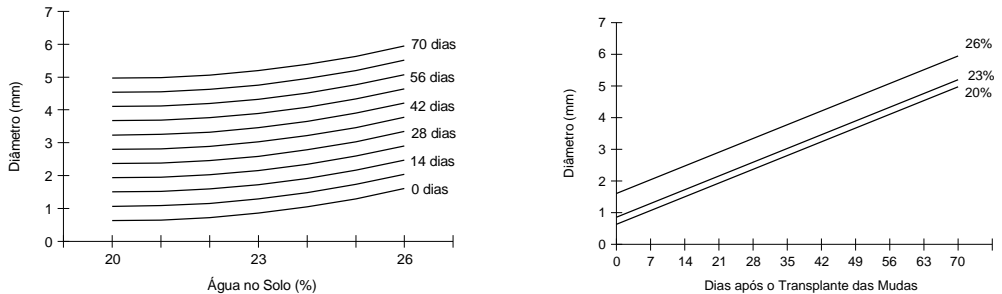

1 B. brizantha $\$=12,6573-1,1885 * * \mathrm{X}+0,02936 * * \mathrm{X}^{2}+0,06201 * * \mathrm{D}$

$\mathrm{R}^{2}=0,95$
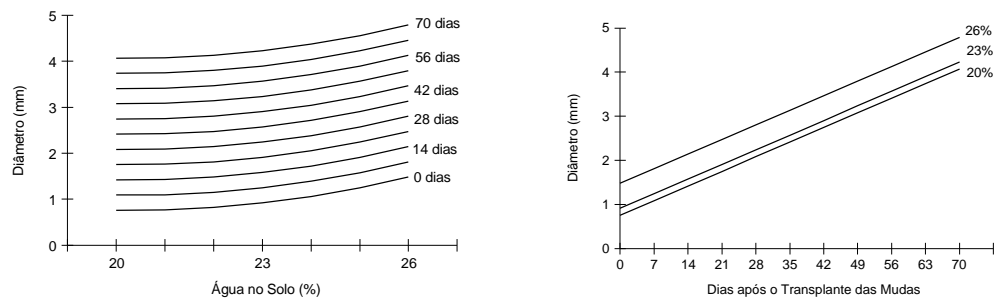

2 B. brizantha $\$=10,0076-0,9107 * * \mathrm{U}+0,02241 * * \mathrm{U}^{2}+0,04732 * * \mathrm{D}$

$\mathrm{R}^{2}=0,96$
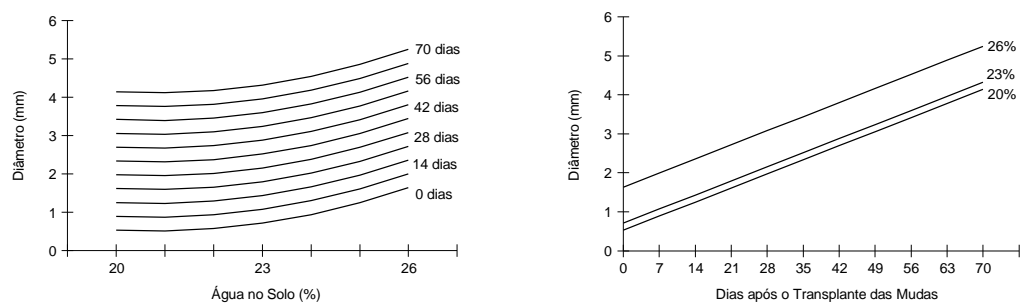

3 B. brizantha $\$=18,3404-1,7176 * * \mathrm{X}+0,04135^{* *} \mathrm{X}^{2}+0,05157 * * \mathrm{D} \quad \mathrm{R}^{2}=0,94$

A Figura 6 apresenta o diâmetro do caule das plantas dos eucaliptos, em convivênciacom zero, uma, duas e três plantas de $B$. brizantha/vaso. Emausência de 
B. brizantha, a equação de regressão múltipla representa o efeito quadrático do teor de água no solo eépoca de avaliação. Mas, em presença de uma, duas e três plantas $B$. Brizantha/vaso, o efeito foi quadrático para o teor de água no solo e linear para época de avaliação no crescimento em diâmetro.

Com base nas equações de regressão estimadas do diâmetro do caule, pela Figura 6, aos 70 dias após o transplante das mudas, observa-se que, em ausência de $B$. brizantha, o máximo de diâmetro estimado foi de $8,2 \mathrm{~mm}$ e $6,4 \mathrm{~mm}$ para os teores $26 \%$ e $20 \%$ de água no solo, respectivamente, ou seja, houve redução de $22,0 \%$ do maior teor para o menor teor de água no solo. Em presença de uma B. brizantha/vaso, o diâmetro máximo estimado foi de 5,9 $\mathrm{mm}$ a $26 \%$ e 5,0 $\mathrm{mm}$ a $20 \%$ de água no solo, com redução de $15,3 \%$. Em presença de duas e três plantas de $B$. brizantha, por vaso, o diâmetro máximo estimado foi de 4,8 e 5,2 mm, respectivamente, para $26 \%$ de água no solo; e, a $20 \%$ de água no solo, foi de $4,1 \mathrm{~mm}$ para duas plantas de $B$. brizantha, e 4,2 $\mathrm{mm}$ para três plantas de $B$. brizantha/vaso. Contudo, a redução do maior teor (26\%) para o menor teor de água no solo $(20 \%)$ provocou uma diminuição do diâmetro das plantas de $14,6 \%$ em presença de duas plantas de $B$. brizantha e de $19,2 \%$ em presença de três plantas de B. brizantha/vaso.

Os resultados do diâmetro do caule evidenciam que a presença de $B$. brizantha, competindo com o eucalipto, em um mesmo vaso, reduziu, substancialmente, o diâmetro. Tais resultados da redução do diâmetro foram de $28,0 \%$; $41,5 \%$; e $36,6 \%$ para uma, duas e três plantas de $B$. brizantha, por vaso, respectivamente, a $26 \%$ de água no solo. Nas condições de estresse hídrido (20\%), a redução do diâmetro foi de $21,9 \%$ para uma planta de $B$. brizantha, $35,9 \%$ para duas plantas de $B$. brizantha e $34,4 \%$ para três plantas de $B$. brizantha/vaso, aos 70 dias após o transplante das mudas.

A interferência de uma planta de B. brizantha/vaso, em convivência com o eucalipto, proporcionou redução do diâmetro. Essa redução foi maior no solo com $26 \%$ de água, da ordem de $28 \%$, contra $21,9 \%$ de redução do diâmetro sob estresse hídrico ( $20 \%$ de água). A presença de duas e três plantas de $B$. brizantha/vaso torna esse valor de redução maior ainda, de $41,5 \%$ para o teor $26 \%$ e de $35 \%$ para o teor $20 \%$ de água no solo. Esta maior redução do crescimento em diâmetro do eucalipto ocorreu quando as condições de água no solo foram ótimas em presença de $B$. brizantha. Isto pode ser explicado em virtude do crescimento inicial da gramínea ter sido mais rápido quando comparado ao eucalipto. Durante a condução do experimento observou-se alta intensidade luminosa e temperatura próxima a $30^{\circ} \mathrm{C}, \mathrm{o}$ que favoreceu o crescimento das plantas de $B$. brizantha que é uma planta $\mathrm{C}_{4}$ (DUKE, 1987) emrelação ao eucalipto queé uma planta $C_{3}$ (LUDLOW, 1980).

\section{CONCLUSÕES}

Os maiores valores de altura total e diâmetro do caule das plantas de $E$. citriodora e E. grandis foram observados em solos com maior teor de água no solo (26\%), emausência B. brizantha. 
A presença $B$. brizantha reduziu a altura total e o diâmetro do caule dos eucaliptos para os três teores de água no solo. Todavia, a maior redução percentual, tanto da altura quanto do diâmetro, ocorreu quando as plantas dos eucaliptos foram submetidas a $26 \%$ de água no solo.

grandis.

E. citriodora foi mais sensível à convivência com $B$. brizantha que $E$.

\section{BIBLIOGRAFIA CITADA}

BARLOW, E.W.R. Water relations of the mature leaf. In: DALE, J.E., MILTHORPE, F.L. (Eds.). The growth and functioning of leaves.Cambridge: University Press, 1983. p.315-345.

CLARK, R.B. Characterization of phosphatase of intact maize roots. J. Agric. Food. Chem. ,v.23,p.458-460, 1975.

DEFELIPO, B.V., RIBEIRO, A. C. Análise química do solo (metodologia). Viçosa, MG: UFV,Imp.Univ., 1981.17p.(Boletim de extensão, 29)

DUKE, S.O. Weed physiology, reproduction and ecophysiology. Boca Raton: CRC; 1987. v.1,157p.

EMPRESA BRASILEIRA DE PESQUISA AGROPECUÁRIA - EMBRAPA. Manual de métodosdeanálise desolo. 2. ed. Rio de Janeiro, 1997.212p.

GHOLZ, H.L., EWEL, K.C., TESKEY, R.O. Water and forest productivity. For._Ecol. Manag., v.30, n.1, p.1-18, 1990.

HSIAO, T.C., ACEVEDO, E. Plant responses to water deficits water-use efficiency, and drought resistence. Agric. Meteor., v.59, p.59-84, 1974.

HSIAO, T.C. Plant responses to water stress. Ann. Ver. Plant Physiol.,v.24,p.519-570, 1973.

KRAMER, P.J. Water relations of plants. New York: Academic, 1983. 89p.

KUHNS, M.R., GJERSTAD, D.H. Photosyntathe allocation in lobloly pine (Pinus taeda) seedlings as affected by moisture stress. Can.J.For. Res., v.18, p.265-291, 1988.

LOCATELLY, E., DOLL, J.D. Competência y alelopatis. In: DOLL, J.D. (Ed.). Manejo y controldemalezas en el trópico. Cali:CIAT, 1977.p.25-34. 
LUDLOW, M.M. Adaptative significance of stomatal responses to water stress. In: TURNER, N.C., KRAMER, P.J. (Eds.). Adaptation of plants to water and high temperaturestress. New York: John-Wiley, 1980. p.123-138.

NAMBIAR, E,K.S. Significance of first-order lateral roots on the growth of young radiata pine under enviromental stress. Aust.For. Res., v.14, p.187-199, 1984.

PEREIRA, J.S. Relações hídricas das árvores. Agr.Lusitana, v.39, n.2/3, p.155-173, 1979.

PITLLI, R.A., KARAM, D. Ecologia das plantas daninhas e sua interferência em culturas florestais. In: SEMINÁRIO: PLANTAS DANINHAS E O USO DE HERBICIDAS EM REFLORESTAMENTO, 1, Rio de Janeiro, 1988. Anais... Rio de Janeiro, 1988. p.1-20.

RICHARDS, L.A. Methods of measuring soil moisture tension. Soil Sci.,v.15,p.95-112, 1949.

SILVA, W. Tolerância de Eucalyptus spp. a herbicidase a eficiência desses produtos no controle de plantas daninhas. Viçosa, MG: UFV, 1993. 86p. Tese (Mestrado em Fitotecnia)-Universidade Federal de Viçosa, 1993.

SILVA, W., Interferência de B. brizantha sobre Eucalyptus citriodora e E. grandis, cultivados em solos com diferentes teores de água. Viçosa, MG: UFV, 1997. 89p. Tese (Doutorado emFitotecnia) - Universidade Federal de Viçosa, 1997.

TSCHAPLINSKI, T.J. The effects of root restriction on grouth relations and senescence in europan alder (Almus gluminosa Gaerth). Toronto: University of Toronto. 1982. 96p. Tese(Magisterin Philosophy) - University of Toronto, 1982.

TYREE, M.T., FLANAGAN, L.B., ADANSON, N. Response of trees drought. In: HUTCHINSON, M. (Eds.). Effects of atmospheric pollutants on forests, wetlands and agricultural ecosystems. Berlim: Spinger-Verlag, 1987. p.201-216.

VOELLER, J.E. YOUNG,J.F.HOLT,H.A. Seedling pine response to first-year vegetation control.Proc.Sonthern Weed Sci.Soc., v.27, p.59-63, 1974. 